\title{
An all-solid-state potentiometric microelectrode for detection of copper in coastal sediment pore water
}

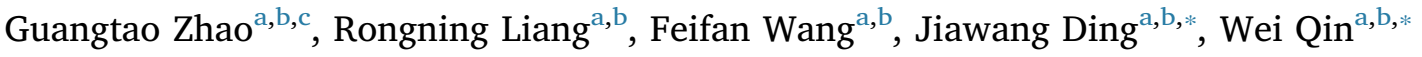 \\ ${ }^{a}$ Key Laboratory of Coastal Environmental Processes and Ecological Remediation, Yantai Institute of Coastal Zone Research (YIC), Chinese Academy of Sciences(CAS), \\ Shandong Provincial Key Laboratory of Coastal Environmental Processes, YICCAS, Yantai Shandong, 264003, China \\ ${ }^{\mathrm{b}}$ Laboratory for Marine Biology and Biotechnology, Qingdao National Laboratory for Marine Science and Technology, Qingdao, China \\ ${ }^{\mathrm{c}}$ University of Chinese Academy of Sciences, Beijing, 100049, China
}

A R T I C L E I N F O

\section{Keywords:}

Ion-selective microelectrodes

Potentiometry

Pore water

Copper

\begin{abstract}
A B S T R A C T
Potentiometric microelectrodes are regarded as promising probes for ion sensing when only limited sample volumes are available. In this work, an all-solid-state ion-selective microelectrode (IS $\mu \mathrm{E}$ ) has been developed by coating ionophore-based ion-selective membrane on a poly(3,4-ethylenedioxythiophene)-poly(sodium 4-styrenesulfonate) modified gold wire with a diameter of $14 \mu \mathrm{m}$ for detection of copper. Under the optimized conditions, the proposed all-solid-state $\mathrm{Cu}^{2+}$-IS $\mu \mathrm{E}$ shows a Nernst response toward $\mathrm{Cu}^{2+}$ in $0.5 \mathrm{M} \mathrm{NaCl}$ in the range from $2.5 \times 10^{-7}$ to $2.5 \times 10^{-4} \mathrm{M}$ with a detection limit of $4.0 \times 10^{-8} \mathrm{M}$. Additionally, the $\mathrm{Cu}^{2+}$-IS $\mu \mathrm{E}$ has been used for monitoring the vertical distribution profile of $\mathrm{Cu}^{2+}$ in coastal sediment pore water with a small volume (e.g., $300 \mu \mathrm{L}$ ). The results agree well with those obtained by anodic stripping voltammetry, which indicates that the proposed potentiometric technique based on the all-solid-state IS $\mu \mathrm{E}$ is promising for detection of $\mathrm{Cu}^{2+}$ in coastal sediment pore water. The method for the preparation of the IS $\mu \mathrm{E}$ can be extended to detect other heavy metal ions in sediments by using different ion-selective membranes.
\end{abstract}

\section{Introduction}

Dissolved heavy metals in contaminated sediment pore waters are indicative of their bioavailabilities for benthic organisms and consequently, implicate possible human exposure through the aquatic food chain transfer [1]. Moreover, the environmental behaviors of heavy metals are directly associated with their concentrations in the sediment pore water [2]. Therefore, it is highly desired for reliable measurements of heavy metal ions in sediment pore water.

The general procedures for detection of heavy metal ions in sediment pore water are based on the on-the-spot extraction of the pore water by centrifugation and squeezing combined with the subsequent laboratory chemical analysis [1,3]. In recent years, DET (diffusive equilibration in thinfilms) and DGT (diffusive gradient in thinfilms) techniques have been proposed for determination of heavy metal ions in sediment pore water [4-6]. However, these techniques suffer from problems of complex and time-consuming procedures.

Electrochemical microsensors have shown a promising application in solving the challenges in environmental chemistry and marine science [7]. As a simple, field-portable, and widespread electrochemical methodology, potentiometry based on polymeric membrane ion-selective electrodes (ISEs) is widely used for selective and sensitive detection of cations and anions in biological and environmental samples [8]. One unique feature of these ISEs is that the drastical decrease in sample volume does not deteriorate the detection limit of the electrode $[9,10]$. Therefore, an ion-selective microelectrode (IS $\mu \mathrm{E}$ ) is a promising probe for ion sensing when limited sample volumes are available. More importantly, the IS $\mu \mathrm{E}$ shows a great potential for in situ measurement of heavy metal ions in pore water.

Since the discovery in 1960s, various kinds of the potentiometric microelectrodes have been developed [11-13]. Among them, the glass micropipettes with the diameters from a few tens of $\mu \mathrm{m}$ to a few tens of $\mathrm{nm}$ have been used to develop the potentiometric microelectrodes to monitor ion activities in matrixes such as living organisms [11] and pore waters [14]. Additionally, the glass micropipette-based potentiometric microelectrodes have also been applied to map the ion fluxes in plant tissues and investigate corrosion processes [15-18]. They have also been adopted as probes of scanning electrochemical microscopy (SECM) [19-21]. However, such kind of the microelectrodes suffers from problems of difficult handling, fragility and short lifetimes [11]. In

\footnotetext{
* Corresponding authors at: Key Laboratory of Coastal Environmental Processes and Ecological Remediation, Yantai Institute of Coastal Zone Research (YIC), Chinese Academy of Sciences(CAS), Shandong Provincial Key Laboratory of Coastal Environmental Processes, YICCAS, Yantai Shandong, 264003, China.

E-mail addresses: jwding@yic.ac.cn (J. Ding), wqin@yic.ac.cn (W. Qin).
} 
recent years, all-solid-state potentiometric microelectrodes with the ease of preparation and robustness have been developed [11,22]. For example, Tóth and coworkers proposed an all-solid-state potassiumselective microelectrode with polypyrrole as solid contact [22]. Brown and coworkers prepared a glass nanopore-based all-solid-state ion-selective microelectrode to probe the distribution of ionic species at the micro- or submicrometer-length scale [23]. However, most of these potentiometric microelectrodes were used to detect the common electrolytes such as $\mathrm{K}^{+}, \mathrm{Na}^{+}, \mathrm{Ca}^{2+}, \mathrm{Li}^{+}$and $\mathrm{Cl}^{-}$. The aim of this work is to develop an all-solid-state IS $\mu \mathrm{E}$ for detection of heavy metal ions in coastal sediment pore water. For this purpose, the IS $\mu \mathrm{E}$ has been prepared by coating ionophore-based ion-selective membrane on a poly (3,4-ethylenedioxythiophene)-poly(sodium 4-styrenesulfonate) modified gold wire. By using $\mathrm{Cu}^{2+}$ as a model of heavy metals, the characteristics for the $\mathrm{Cu}^{2+}$-IS $\mu \mathrm{E}$ have been investigated.

\section{Experimental section}

\subsection{Materials}

All the information of the chemicals is available in the Supporting Information.

\subsection{Fabrication of the gold microelectrode}

A gold wire with a diameter of $14 \mu \mathrm{m}$ (Alfa Aesar, 99.9\%) was attached to a copper wire by using a graphite-filled silver glue, and then dried for $4 \mathrm{~h}$ at $80^{\circ} \mathrm{C}$. The gold wire was carefully inserted in a glass capillary tube (with a diameter of $1.0 \mathrm{~mm}$ ), and the copper wire was fixed by casting non-conducting epoxy glue at the stem end of the capillary tube [24,25]. The glass was then flame-fuse sealed around the gold wire from the tip (Fig. S1). Finally, the sealed end was polished with sand paper and a $0.05 \mu \mathrm{m}$ aluminum oxide suspension. The microelectrode was immersed in $1.0 \mathrm{M} \mathrm{HNO}_{3}$ for $15 \mathrm{~min}$, and then cleaned ultrasonically in deionized water and ethanol, respectively. The prepared gold microelectrode is denoted as the AupE eletrode. The voltammetric characteristics of the AupE are illustrated in Fig. S2, which shows a sigmoid-shaped voltammogram [22].

\subsection{Preparation of the all-solid-state $\mathrm{Cu}^{2+}-\mathrm{IS} \mu \mathrm{E}$}

The conducting polymer poly(3,4-ethylenedioxythiophene)-poly (sodium 4-styrenesulfonate) (PEDOT(PSS)) was deposited on the surface of the Au $\mathrm{E}$ electrode by galvanostatic electrochemical polymerization to prepare the Au $\mu$ E/PEDOT(PSS) electrode [26,27]. More details are shown in the Supporting Information. $250 \mathrm{mg}$ of the membrane components, including $1.00 \mathrm{wt} \% \mathrm{Cu}^{2+}$ ionophore (ETH1062), $1.02 \mathrm{wt} \%$ sodium tetrakis[3,5-bis (trifluoromethyl) phenyl]borate (NaTFPB), $65.32 \mathrm{wt} \%$ 2-nitrophenyl octyl ether (o-NPOE), and $32.66 \mathrm{wt}$ $\%$ poly(vinyl chloride) PVC, was dissolved in $2 \mathrm{~mL}$ of tetrahydrofuran (THF). Then, $0.8 \mu \mathrm{L}$ of the $\mathrm{Cu}^{2+}$-selective membrane cocktail solution was applied on the surface of the PEDOT(PSS) film. After being dried,

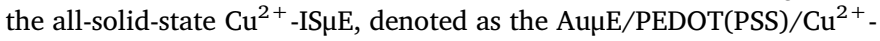
ISE, was conditioned in a $10^{-3} \mathrm{M} \mathrm{CuCl}_{2}$ solution for $1 \mathrm{~h}$. For comparison, the $\mathrm{Au \mu E} / \mathrm{Cu}^{2+}$-ISE was prepared by coating the ion-selective membrane on the bare AupE.

\subsection{Apparatus and measurements}

Electromotive force (EMF) measurements were carried out at room temperature using a CHI 760C electrochemical workstation (Shanghai Chenhua Apparatus Corporation, China). An Ag/AgCl/3 M KCl microelectrode with a diameter of $10 \mu \mathrm{M}$ was used as the reference electrode [28]. Cyclic voltammetry (CV) and electrochemical impedance spectroscopy (EIS) measurements were carried out in $0.1 \mathrm{M} \mathrm{KCl}$ solution by

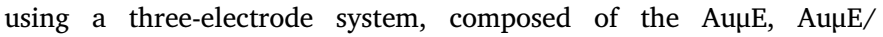

PEDOT(PSS) or AußE/PEDOT(PSS)/ISE electrode as working electrode, the $\mathrm{Ag} / \mathrm{AgCl} / 3 \mathrm{M} \mathrm{KCl}$ microelectrode as reference electrode and a $\mathrm{Pt}$ wire as counter electrode.

\subsection{Sample analysis}

In order to investigate the vertical distribution profile of $\mathrm{Cu}^{2+}$ in coastal sediment pore water, the sediment samples were collected on January 12, 2018 (Fig. S3). Details of the sample preparation are available in the Supporting Information. Before analysis, the samples were acidified to $\mathrm{pH} 2.0$ with $\mathrm{HNO}_{3}$. The standard addition method was applied to determine the concentration of $\mathrm{Cu}^{2+}$ in $300 \mu \mathrm{L}$ of each sample solution by using the proposed all-solid-state $\mathrm{Cu}^{2+}$-IS $\mu \mathrm{E}$ [29]. For comparison, the concentrations of $\mathrm{Cu}^{2+}$ in the coastal sediment pore water were also determined by the $797 \mathrm{~V}$ A computrace via anodic stripping voltammetry (ASV, Metrohm Ltd., Switzerland).

\section{Results and discussion}

Due to its high conductivity, large redox capacitance and good thin film-forming properties [30], the PEDOT(PSS) film has been studied and used as the ion-to-electron transducer in the design of the solid-

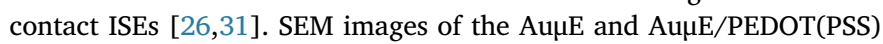
electrodes reveal that the AupE electrode shows a smooth surface with a diameter of $14 \mu \mathrm{m}$, while the Au $\mathrm{E} / \mathrm{PEDOT}(\mathrm{PSS})$ electrode shows a compact and rough morphology (Fig. S4) [32]. CV and EIS measurements were also carried out to evaluate the electrochemical char-

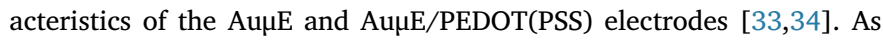
shown in Fig. 1A, a capacitive process with a near-rectangular shape from -0.5 to $0.5 \mathrm{~V}$ was observed except the oxygen reduction peak at ca $-0.35 \mathrm{~V}$ [35]. The symmetrical shape of the CV reveals that the PEDOT(PSS) film has a high reversibility for the doping process [36]. Moreover, the anodic currents at $0 \mathrm{~V}$ vary linearly with increasing the scan rate (Fig. S5), indicating that both ion and electron transports in the PEDOT(PSS) film are fast. Fig. 1A also shows that the capacitive current of the bare microelectrode is only at $10^{-10} \mathrm{~A}$ levels, which is due to the high resistance of the microelectrode. However, when the $\mathrm{Au} \mu \mathrm{E}$ is modified with the PEDOT(PSS) film, more than 100 -fold increase of the capacitive current can be observed. This phenomenon is similar to the conventional electrode [37] and indicates that the presence of PEDOT(PSS) film enhances the redox capacitance of the electrode.

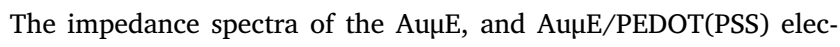
trodes were compared. As shown in Fig. 1B, both electrodes show near $90^{\circ}$ capacitive lines with the absence of the high-frequency semicircle, which indicates that there are fast charge transfers at the interfaces for both electrodes. However, according to the equation, C $=-1 /\left(2 \pi f Z^{\prime \prime}\right)$, where $f$ is the lowest frequency used to record the spectra $(0.01 \mathrm{~Hz}), \mathrm{Z}$ " is the impedance at this frequency $[33,34]$, the redox capacitance of the AupE/PEDOT(PSS) electrode $(252.8 \pm 11.9 \mathrm{nF})$ was found to be much higher than that of AupE (1.0 nF). This phenomenon is in accordance with that obtained by CV. Therefore, the PEDOT(PSS) film with a sufficiently high bulk (redox) capacitance was employed for preparing the all-solid-state $\mathrm{Cu}^{2+}-\mathrm{IS} \mu \mathrm{E}$ [26]. It should be noted that the diffusion resistance $\left(R_{D}\right)$ of the AupE/PEDOT(PSS) is calculated to be $11.1 \pm 2.8$ $\mathrm{K} \Omega$ when fitting the equivalent circuit (Fig. 1B) [26]. According to the equation $R_{D}=\tau_{D} / C_{L}$, a diffusion time constant $\left(\tau_{D}\right)$ of $2.9 \pm 0.7 \mathrm{~ms}$ can be obtained. The low frequency relation process described by the time constant increases with the thickness of the PEDOT(PSS) film and might be connected with the long-term drift of the electrode potential [38].

The impedance spectrum of the AupE/PEDOT(PSS)/ $\mathrm{Cu}^{2+}$-ISE was also investigated (Fig. 1C). The bulk capacitance of the AupE/PEDOT(PSS) $/ \mathrm{Cu}^{2+}$-ISE was calculated to be $197.3 \pm 22.2 \mathrm{nF}$ when fitting the equivalent circuit (average error, $\chi^{2}=0.06$ ) [39], which is lower than that of the AupE/PEDOT(PSS) $(252.8 \pm 11.9 \mathrm{nF})$. However, due to the thin polymeric membrane applied (a few micrometers) and the 

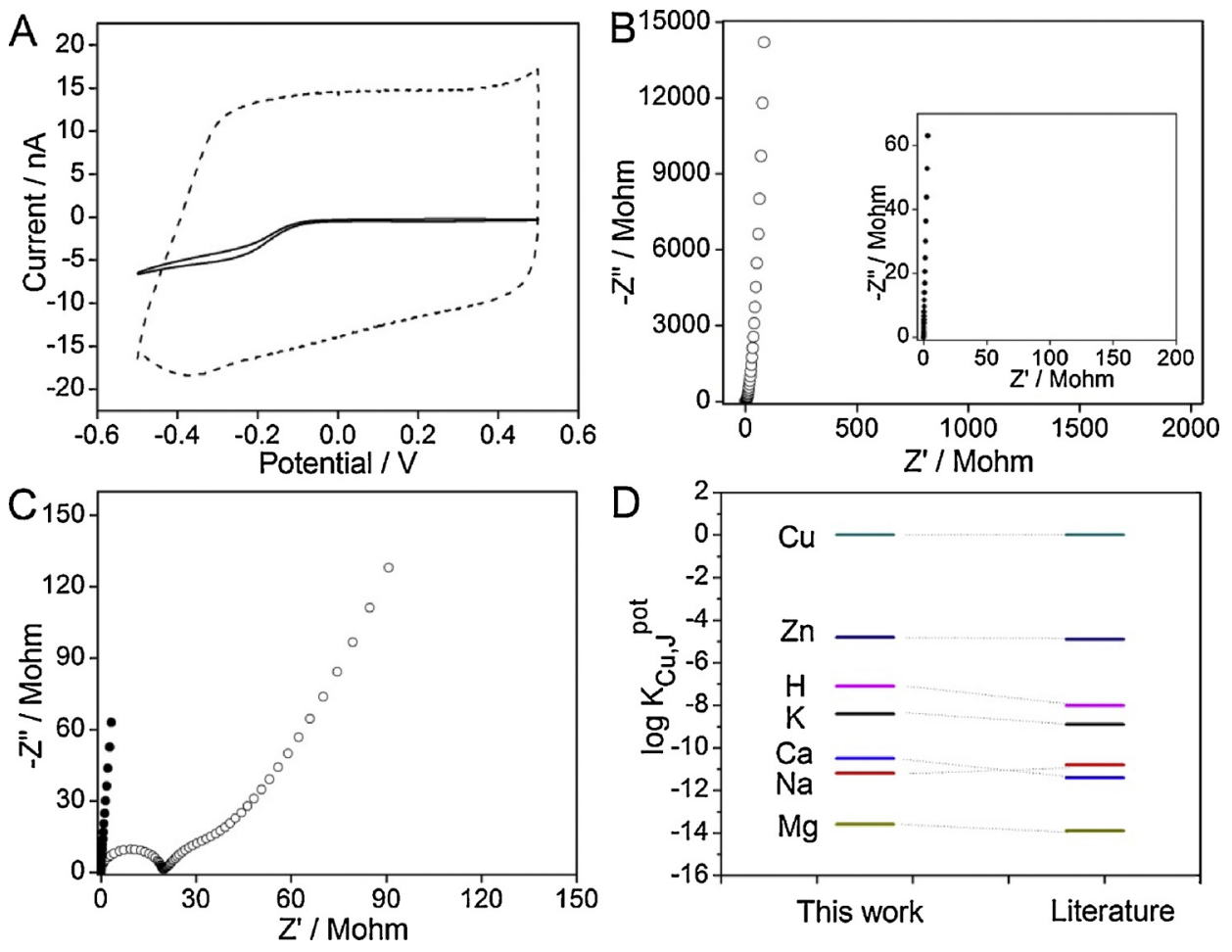

Fig. 1. (A) Cyclic voltammograms of the AunE (line), and AupE/PEDOT(PSS) electrodes (dash). (B) Impedance spectra for the $\mathrm{Au} \mu \mathrm{E}(\mathrm{O})$ and AunE/PEDOT(PSS) electrodes (O) in $0.1 \mathrm{M} \mathrm{KCl}$ solution recorded at the open-circuit potentials. The inset shows magnification of the impedance

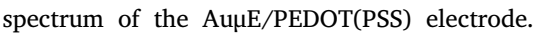
(C) Impedance spectra for the AupE/ PEDOT(PSS) electrode (O) and AupE/ PEDOT(PSS)/ $\mathrm{Cu}^{2+}$-ISE (O) in $0.1 \mathrm{M} \mathrm{KCl} \mathrm{solu-}$ tion recorded at the open-circuit potentials. Scan rate, $50 \mathrm{mV} \mathrm{s}^{-1}$; frequency range, $0.01 \mathrm{~Hz}$ $10 \mathrm{kHz}$; excitation amplitude, $100 \mathrm{mV}$. (D) Comparison of the selectivity coefficients for the present $\mathrm{Cu}^{2+}$-selective membrane obtained with the separate solution method [40] and reported in the literature [41]. high charge transfer process of the AupE, such capacitance decrease is quite low.

The selectivity was examined by the separated solution method [40]. As shown in Fig. 1D, the selectivity coefficients of the $\mathrm{Cu}^{2+}$-selective membrane are consistent with those in the literature [41]. Moreover, according to the determined selectivity coefficients toward sodium ions, a theoretical detection limit can be evaluated to be $8 \times 10^{-13} \mathrm{M}$ for copper ions in the presence of $0.5 \mathrm{M}$ sodium ions [42].

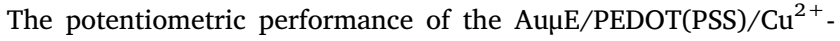
ISE was investigated in deionized water (Fig. 2A-a). The electrode exhibits a stable response with a slope of $30.7 \pm 1.3 \mathrm{mV} /$ decade $\left(R^{2}=0.997\right)$. The detection limit calculated as the intersection of the two lines is $1.6 \times 10^{-8} \mathrm{M}$ (Fig. 2B-a). In the background solution of $0.5 \mathrm{M} \mathrm{NaCl}$, the proposed all-solid-state $\mathrm{Cu}^{2+}-\mathrm{IS} \mu \mathrm{E}$ shows a linear response in the range of $2.5 \times 10^{-7}-2.5 \times 10^{-4} \mathrm{M}$ with a slope of $28.1 \pm 1.8 \mathrm{mV} /$ decade $\left(\mathrm{R}^{2}=0.999\right)$ (Fig. $2 \mathrm{~A}-\mathrm{b}$ ). In the presence of high concentrations of interfering ions, the primary ions in the outer boundary layer of the membrane can be replaced. Therefore, substantial fluxes of copper ions from the membrane into the sample could be generated and deteriorate the detection limit of the electrode [43]. Indeed, the detection limit found for the proposed electrode in $0.5 \mathrm{M}$ $\mathrm{NaCl}$ is $4.0 \times 10^{-8} \mathrm{M}$, which is higher than that obtained in deionized water (Fig. 2B-b). Interestingly, the detection limit for the microsensor is lower than that of the conventional all-solid-state bulk $\mathrm{Cu}^{2+}$-ISE $\left(4.0 \times 10^{-7} \mathrm{M}\right)$ under the same conditions (Figs. 2A-c and B-c). This phenomenon may be attributed to the small size of microelectrode, which makes the ion diffusional transport more efficient. In this case, the primary ions leaching from the membrane into the sample solution, which deteriorates the detection limit of the microelectrode, could be expelled via the rapid diffusion process at the membrane/solution interface $[43,44]$.

The effect of sample $\mathrm{pH}$ on the $\mathrm{Cu}^{2+}$-IS $\mu \mathrm{E}$ response was investigated. According to the determined selectivity coefficients of the $\mathrm{Cu}^{2+}$-IS $\mu \mathrm{E}$ toward $\mathrm{H}^{+}\left(\log \boldsymbol{K}_{I J}^{\text {pot }}=-7.1\right)$, the $\mathrm{Cu}^{2+}$-IS $\mu \mathrm{E}$ was insensitive to sample $\mathrm{pH}$. Indeed, as shown in Fig. S6, a stable EMF value was obtained in $10^{-5} \mathrm{M} \mathrm{CuCl}_{2}$ in the presence of $0.5 \mathrm{M} \mathrm{NaCl}$ over a wide $\mathrm{pH}$ range. Additionally, the short-term potential stability was investigated. According to the chronopotentiograms (Fig. S7), the potential drift of
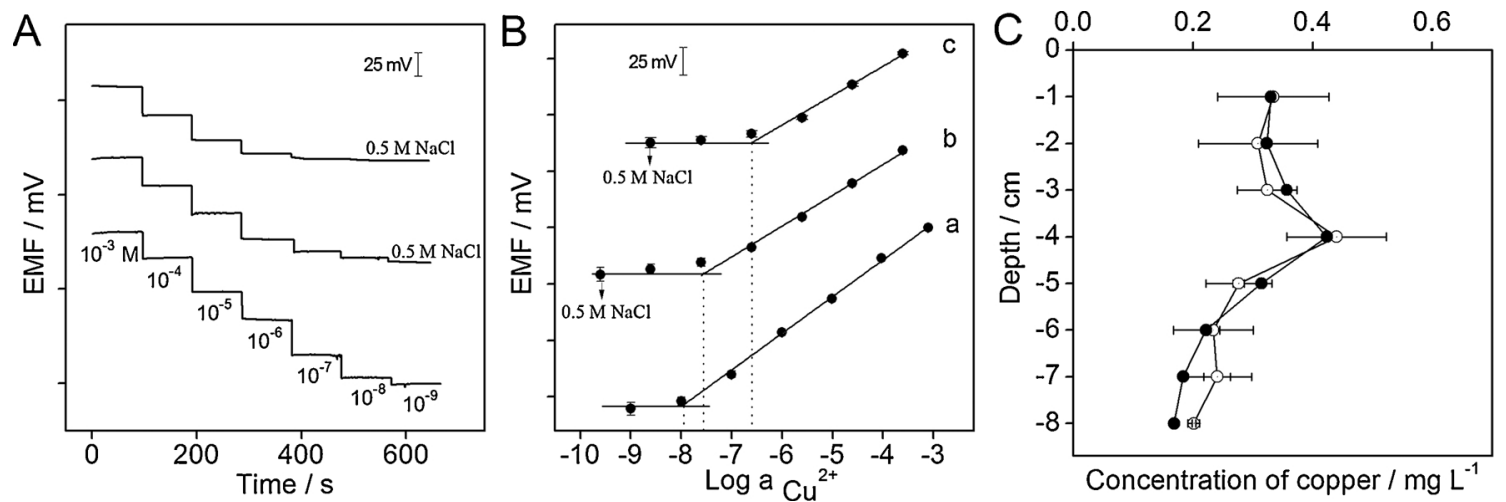

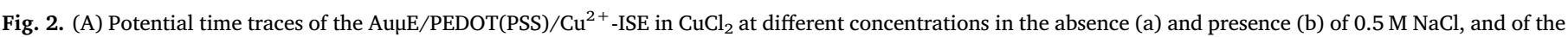

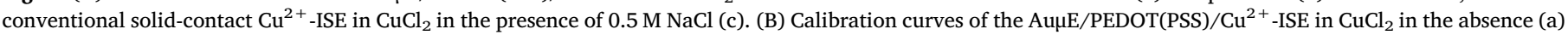

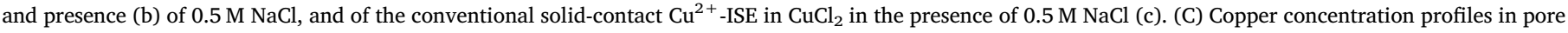
water obtained by the proposed sensor (hollow circle) and ASV (solid circle). Error bars represent one standard deviation for three measurements. 


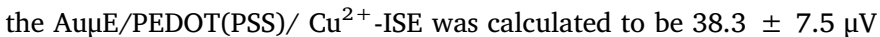
$\mathrm{s}^{-1}$ when using the applied currents of $\pm 0.01 \mathrm{nA}$, indicating that the microelectrode could obtain a stable potential response. Indeed, a solidcontact microelectrode with a potential drift of $0.063 \mathrm{mV} \mathrm{min}^{-1}$ has been reported by using PEDOT nanowires as ion-to-electron transducer [45]. Moreover, several other solid-contact microelectrodes have also been developed and show acceptable stabilities and reproducibilities

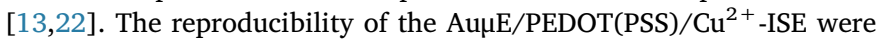
evaluated (Fig. S8). Experiments reveal that the proposed electrode exhibits good reproducibility.

In order to demonstrate the feasibility of the proposed AupE/ PEDOT(PSS)/ $\mathrm{Cu}^{2+}$-ISE for environmental analysis, the contents of copper ions in the coastal sediment pore water samples were detected by the standard addition method. The volumes of the pore water samples obtained from the coastal sediment core were very limited, especially when the depths were up to $6 \mathrm{~cm}$. Therefore, the proposed potentiometric technique based on the all-solid-state IS $\mu \mathrm{E}$ is promising for detection of $\mathrm{Cu}^{2+}$ in the sediment pore water samples with small volumes. The depth profile of copper in pore water is shown in Fig. 2C, which shows the observed copper concentrations in the range of 0.15 to $0.45 \mathrm{mg} \mathrm{L}^{-1}$ and a peak concentration of $0.42 \mathrm{mg} \mathrm{L}^{-1}$ at the depth of $4 \mathrm{~cm}$. Fig. 2C also shows that the depth profile of copper determined by the proposed $\mathrm{Cu}^{2+}$-IS $\mu \mathrm{E}$ is in close agreement with those obtained by ASV.

\section{Conclusions}

In this work, an all-solid-state IS $\mu \mathrm{E}$ based on the electrodeposited PEDOT(PSS) has been developed for detection of copper ions in coastal sediment pore water. The proposed sensor shows favorable potentiometric performance in terms of detection limit, selectivity, and potential stability. Additionally, the all-solid-state $\mathrm{Cu}^{2+}$-IS $\mu \mathrm{E}$ is promising for detection of $\mathrm{Cu}^{2+}$ in the sediment pore water samples with small volumes. The proposed method is versatile and can be used for detection of other heavy metal ions in sediments by using different ion-selective membranes. With the introduction of the solid-contact pototentiometric microsensors for pore water analysis, the perturbation of the profiles of the heavy metal ions in the sediment pore water can be avoided. Thus, the electrode shows potential promise for in situ measurements of heavy metal ions in pore water. The related studies are currently in progress in this laboratory.

\section{Acknowledgements}

This work was financially supported by the Instrument Developing Project of the Chinese Academy of Sciences (Y728021021), the National Natural Science Foundation of China $(21677172,21575158)$, the National Key Research and Development Program of China (2016YFC1400700), the Taishan Scholar Program of Shandong Province (TS20081159), and the Youth Innovation Promotion Association of CAS (2014190).

\section{Appendix A. Supplementary data}

Supplementary material related to this article can be found, in the online version, at doi:https://doi.org/10.1016/j.snb.2018.09.125.

\section{References}

[1] H.H. Liu, L.J. Bao, W.H. Feng, S.P. Xu, F.C. Wu, E.Y. Zeng, A multisection passive sampler for measuring sediment porewater profile of dichlorodiphenyltrichloroethane and its metabolites, Anal. Chem. 85 (2013) 7117-7124.

[2] B. Sundby, M. Caetano, C. Vale, C. Gobeil, G.W. Luther, D.B. Nuzzio, Root-induced cycling of lead in salt marsh sediments, Environ. Sci. Technol. 39 (2005) 2080-2086.

[3] S.D. Supowit, I.B. Roll, V.D. Dang, K.J. Kroll, N.D. Denslow, R.U. Halden, Active sampling device for determining pollutants in surface and pore water - the in situ sampler for biphasic water monitoring, Sci. Rep. 6 (2016) 1-9.

[4] W. Davison, H. Zhang, G.W. Grime, Performance characteristics of gel probes used for measuring the chemistry of pore waters, Environ. Sci. Technol. 28 (1994) 1623-1632.

[5] W. Davlson, H. Zhang, In situ speciation measurements of trace components in natural waters using thin-film gels, Nature 367 (1994) 546-548.

[6] C.S. Zhang, S. Ding, D. Xu, Y. Tang, M.H. Wong, Bioavailability assessment of phosphorus and metals in soils and sediments: a review of diffusive gradients in thin films (DGT), Environ. Monit. Assess. 186 (2014) 7367-7378.

[7] C.E. Reimers, Applications of microelectrodes to problems in chemical oceanography, Chem. Rev. 107 (2007) 590-600.

[8] J. Bobacka, A. Ivaska, A. Lewenstam, Potentiometric ion sensors, Chem. Rev. 108 (2008) 329-351.

[9] A. Malon, T. Vigassy, E. Bakker, E. Pretsch, Potentiometry at trace levels in confined samples: ion-selective electrodes with subfemtomole detection limits, J. Am. Chem. Soc. 128 (2006) 8154-8155.

[10] N. Rubinova, K. Chumbimuni-Torres, E. Bakker, Solid-contact potentiometric polymer membrane microelectrodes for the detection of silver ions at the femtomole level, Sens. Actuators. B-Chem. 121 (2006) 135-141.

[11] E. Bakker, E. Pretsch, Nanoscale potentiometry, TrAC, Trends Anal. Chem. 27 (2008) 612-618.

[12] A. Numnuam, K.Y. Chumbimuni-Torres, Y. Xiang, R. Bash, P. Thavarungkul, P. Kanatharana, E. Pretsch, J. Wang, E. Bakker, Aptamer-based potentiometric measurements of proteins using ion-selective microelectrodes, Anal. Chem. 80 (2008) 707-712.

[13] S.V. Lamakaa, M.G. Tarybaa, M.L. Zheludkevichb, M.G.S. Ferreira, Novel solidcontact ion-selective microelectrodes for localized potentiometric measurements, Electroanalysis 21 (2009) 2447-2453.

[14] W.A. Timms, M.J. Hendry, Real-time analysis of small volume samples with micro ion-selective electrodes, Ground. Water. Monit. R. 24 (2004) 67-72.

[15] M.A. Piñeros, J.E. Shaff, L.V. Kochian, Development, characterization, and application of a cadmium-selective microelectrode for the measurement of cadmium fluxes in roots of thlaspi species and wheat, Plant Physiol. 116 (1998) 1393-1401.

[16] L. Li, X. Liu, W.J. Peijnenburg, J. Zhao, X. Chen, J. Yu, X.B. Chen, J.B. Yu, H.F. Wu, Pathways of cadmium fluxes in the root of the halophyte Suaeda salsa, Ecotox. Environ. Safe. 75 (2012) 1-7.

[17] J. Church, S.M. Armas, P.K. Patel, K. Chumbimuni-Torres, W.H. Lee, Development and characterization of needle-type ion-selective microsensors for in situ determination of foliar uptake of $\mathrm{Zn}^{2+}$ in citrus plants, Electroanalysis 29 (2017) 1-8.

[18] E.A. Zdrachek, A.G. Karotkaya, V.A. Nazarov, K.A. Andronchyk, L.S. Stanishevskii, V.V. Egorov, M.G. Taryba, D. Snihirova, M. Kopylovich, S.V. Lamaka, $\mathrm{H}^{+}$-selective microelectrodes with optimized measuring range for corrosion studies, Sens. Actuators. B-Chem. 207 (2015) 967-975.

[19] R.E. Gyurcsányi, É. Pergel, R. Nagy, I. Kapui, B.T. Thu Lan, K. Tóth, I. Bitter, E. Lindner, Direct evidence of ionic fluxes across ion-selective membranes: a scanning electrochemical microscopic and potentiometric study, Anal. Chem. 73 (2001) 2104-2111.

[20] J. Izquierdo, L. Nagy, Á. Varga, I. Bitter, G. Nagy, R.M. Souto, Scanning electrochemical microscopy for the investigation of corrosion processes: measurement of $\mathrm{Zn}^{2+}$ spatial distribution with ion selective microelectrodes, Electrochim. Acta 59 (2012) 398-403.

[21] J.G. Ummadi, C.J. Downs, V.S. Joshi, J.L. Ferracane, D. Koley, Carbon-based solidstate calcium ion-selective microelectrode and scanning electrochemical microscopy: a quantitative study of $\mathrm{pH}$-dependent release of calcium ions from bioactive glass, Anal. Chem. 88 (2016) 3218-3126.

[22] R.E. Gyurcsányi, A.-S. Nybäck, A. Ivaska, K. Tóth, G. Nagy, Novel polypyrrole based all-solid-state potassium-selective microelectrodes, Analyst 123 (1998) 1339-1344.

[23] J.H. Shim, J. Kim, G.S. Cha, H. Nam, R.J. White, H.S. White, R.B. Brown, Glass nanopore-based ion-selective electrodes, Anal. Chem. 79 (2007) 3568-3574.

[24] J.W. Mo, B. Ogorevc, Simultaneous measurement of dopamine and ascorbate at their physiological levels using voltammetric microprobe based on overoxidized poly(1,2-phenylenediamine)-coated carbon fiber, Anal. Chem. 73 (2001) 1196-1202.

[25] P. Salazar, M. Martin, R. Roche, J.L. Gonzalez-Mora, R.D. O’Neill, Microbiosensors for glucose based on prussian blue modified carbon fiber electrodes for in vivo monitoring in the central nervous system, Biosens. Bioelectron. 26 (2010) 748-753.

[26] J. Bobacka, Potential stability of all-solid-state ion-selective electrodes using conducting polymers as ion-to-electron transducers, Anal. Chem. 71 (1999) 4932-4937.

[27] U. Vanamo, E. Hupa, V. Yrjana, J. Bobacka, New signal readout principle for solidcontact ion-selective electrodes, Anal. Chem. 88 (2016) 4369-4374.

[28] T. Kitade, K. Kitamura, S. Takegami, Y. Miyata, M. Nagatomo, T. Sakaguchi, M. Furukawa, Needle-type ultra micro silver/silver chloride reference electrode for use in micro-electrochemistry, Anal. Sci. 21 (2005) 907-912.

[29] Z. Szigeti, I. Bitter, K. Tóth, C. Latkoczy, D.J. Fliegel, D. Günther, E. Pretsch, A novel polymeric membrane electrode for the potentiometric analysis of $\mathrm{Cu}^{2+}$ in drinking water, Anal. Chim. Acta 532 (2005) 129-136.

[30] J.S. Huang, P.F. Miller, J.S. Wilson, A.J. de Mello, J.C. de Mello, D.D.C. Bradley, Investigation of the effects of doping and post-deposition treatments on the conductivity, morphology, and work function of poly(3,4-ethylenedioxy- thiophene)/ poly(styrene sulfonate) films, Adv. Funct. Mater. 15 (2005) 290-296.

[31] U. Vanamo, J. Bobacka, Electrochemical control of the standard potential of solidcontact ion-selective electrodes having a conducting polymer as ion-to-electron transducer, Electrochim. Acta 122 (2014) 316-321.

[32] C.F. Zhou, Z.W. Liu, X.S. Du, S.P. Ringer, Electrodeposited PEDOT films on ITO with a flower-like hierarchical structure, Synthetic. Met. 160 (2010) 1636-1641. 
[33] Z. Mousavi, J. Bobacka, A. Lewenstam, A. Ivaska, Poly(3,4-ethylenedioxy- thiophene) (PEDOT) doped with carbon nanotubes as ion-to-electron transducer in polymer membrane-based potassium ion-selective electrodes, J. Electroanal. Chem. 633 (2009) 246-252.

[34] T.J. Yin, D.W. Pan, W. Qin, All-solid-state polymeric membrane ion-selective miniaturized electrodes based on a nanoporous gold film as solid contact, Anal. Chem. 86 (2014) 11038-11044.

[35] G.A. Crespo, S. Macho, J. Bobacka, F.X. Rius, Transduction mechanism of carbon nanotubes in solid-sontact ion-selective electrodes, Anal. Chem. 81 (2009) 676-681.

[36] C. Ocaña, N. Abramova, A. Bratov, T. Lindfors, J. Bobacka, Calcium-selective electrodes based on photo-cured polyurethane-acrylate membranes covalently at tached to methacrylate functionalized poly(3,4-ethylenedioxythiophene) as solid contact, Talanta 186 (2018) 279-285.

[37] T.J. Yin, D.W. Pan, W. Qin, A solid-contact $\mathrm{Pb}^{2+}$-selective polymeric membrane electrode with nafion-doped poly(pyrrole) as ion-to-electron transducer, J. Solid State Electrochem. 16 (2012) 499-504.

[38] J. Bobacka, M. McCarrick, A. Lewenstam, A. Ivaska, All solid-state poly(viny chloride) membrane ion-selective electrodes with poly(3- octylthiophene) solid internal contact, Analyst 119 (1994) 1985-1991.

[39] G.A. Crespo, S. Macho, F.X. Rius, Ion-selective electrodes using carbon nanotubes as ion-to-electron transducers, Anal. Chem. 80 (2008) 1316-1322.

[40] E. Bakker, E. Pretsch, P. Bühlmann, Selectivity of potentiometric ion sensors, Anal. Chem. 72 (2000) 1127-1133.

[41] W. Qin, R.N. Liang, X.L. Fu, Q.W. Wang, T.J. Yin, W.J. Song, Trace-level potentiometric detection in the presence of a high electrolyte background, Anal. Chem. 84 (2012) 10509-10513.

[42] A. Ceresa, E. Bakker, B. Hattendorf, D. Gunther, E. Pretsch, Potentiometric polymeric membrane electrodes for measurement of environmental samples at trace levels: new requirements for selectivities and measuring protocols, and comparison with ICPMS, Anal. Chem. 73 (2001) 343-351.
[43] T. Sokalski, T. Zwickl, E. Bakker, E. Pretsch, Lowering the detection limit of solvent polymeric ion-selective electrodes. 1. Modeling the influence of steady-state ion fluxes, Anal. Chem. 71 (1999) 1204-1209.

[44] R.J. Forster, Microelectrodes: new dimensions in electrochemistry, Chem. Soc. Rev. 23 (1994) 289-297.

[45] G. Gyetvai, S. Sundblom, L. Nagy, A. Ivaska, G. Nagy, Solid contact micropipette ion selective electrode for potentiometric SECM, Electroanalysis 19 (2007) 1116-1122.

Guangtao Zhao is pursuing a doctor's degree at Yantai Institute of Coastal Zone Research, Chinese Academy of Sciences. His research interest is microelectrodes.

Rongning Liang is currently working as an associate professor at Yantai Institute of Coastal Zone Research, Chinese Academy of Sciences. His research interests focus on potentiometric sensors based on molecularly imprinted polymers.

Feifan Wang is currently working as a research assistant at Yantai Institute of Coastal Zone Research, Chinese Academy of Sciences.

Jiawang Ding is currently working as an associate professor at Yantai Institute of Coastal Zone Research, Chinese Academy of Sciences. From 2016-2017, he did his joint researches at Åbo Akademi University (Finland) and Geneva University (Switzerland). His research interests include electrochemical sensors and biosensors.

Wei Qin received his doctor's degree from Nanjing University in 1998. From 1999 to 2003, he did his postdoctoral researches at Swiss Federal Institute of Technology (ETH), University of South Carolina and University of Michigan, respectively. He has been working as a professor at Yantai Institute of Coastal Zone Research, Chinese Academy of Sciences since 2006. His research interests include chemical sensors and biosensors for environmental analysis. 